\title{
Relationship of psychological factors with daily activities and quality of life in patients with chronic obstructive pulmonary disease in a Chinese rural population
}

\author{
Jing An ${ }^{1}$, Hui Zhou ${ }^{2}$, Ting Yang ${ }^{1}$, Changling Duan², Chenyi Bao ${ }^{2}$, Chun Wan ${ }^{1}$, Yongchun Shen ${ }^{1}$, \\ Fuqiang Wen $^{1}$
}

${ }^{1}$ Department of Respiratory and Critical Care Medicine, Division of Pulmonary Diseases, State Key Laboratory of Biotherapy, West China Hospital, Sichuan University, Chengdu, China; ${ }^{2}$ West China School of Medicine, Sichuan University, Chengdu, China

Contributions: (I) Conception and design: J An, H Zhou; (II) Administrative support: T Yang, F Wen; (III) Provision of study materials or patients: J An, T Yang, C Wan; (IV) Collection and assembly of data: H Zhou, T Yang, C Duan, C Bao, C Wan; (V) Data analysis and interpretation: J An, H Zhou, C Duan, C Bao; (VI) Manuscript writing: All authors; (VII) Final approval of manuscript: All authors.

Correspondence to: Fuqiang Wen, MD, PhD. Department of Respiratory and Critical Care Medicine, Division of Pulmonary Diseases, State Key Laboratory of Biotherapy, West China Hospital, Sichuan University, 37 Guo Xue Xiang, Chengdu 610041, China. Email: wenfuqiang@scu.edu.cn.

\begin{abstract}
Background Chronic obstructive pulmonary disease (COPD) is a major burden and a leading cause of death worldwide. Comorbidities such as gastroesophageal reflux, arrhythmia, musculoskeletal disorders and cancer affect the quality of life of COPD patients. Psychological factors, such as disease perception, active coping with the disease, anxiety and depression may also affect daily activities and quality of life.

Methods: This cross-sectional study surveyed 86 patients from rural Sichuan in China who had grade 1-3 COPD based on the Global Initiative for Chronic Obstructive Lung Disease scale in order to clarify the relationship of psychological factors with daily activities and quality of life. Respondents filled out the following questionnaires: the Brief Illness Perception Questionnaire (as an assessment of disease perception), Utrecht Proactive Coping Competence Questionnaire (active coping), the Hospital Anxiety Depression Scale (anxiety and depression), the Modified Medical Research Council Scale (dyspnea), the Functional Performance Inventory-Short Form (daily activities) and the Clinical COPD Questionnaire (quality of life). Linear regression was used to explore potential relationship of these psychological factors with daily activities and quality of life.
\end{abstract}

Results: Active coping $(\beta=-0.696, \mathrm{P}<0.001)$ was related to less restricted daily activities, and better quality of life was associated with better disease perception $(\beta=0.680, \mathrm{P}<0.001)$ and lower anxiety $(\beta=0.479, \mathrm{P}<0.001)$.

Conclusions: These results suggest that appropriate psychological interventions may benefit COPD patients, which deserves further investigation.

Keywords: Chronic obstructive pulmonary disease (COPD); daily activities; quality of life; psychological factors; rural population

Submitted May 21, 2020. Accepted for publication Oct 12, 2020.

doi: 10.21037/apm-20-1151

View this article at: http://dx.doi.org/10.21037/apm-20-1151

\section{Introduction}

As one of the leading health burdens worldwide, chronic obstructive pulmonary disease (COPD) causes approximately 3 million deaths annually (1), and it is projected to rank among the top four causes of death globally from 2002 to 2030 (2). In 2013, COPD was the third leading cause of death and accounted for more than 0.9 million deaths in China (3). COPD patients show lower physical activity than their healthy counterparts with the same socioeconomic backgrounds (4). COPD 
patients also show lower physical and mental health-related quality of life (HRQoL) (5), and their deteriorating quality of life is often attributable to disease complications such as gastroesophageal reflux, arrhythmia, musculoskeletal disorders, cancer, fatigue, reduced exercise ability, and dyspnea (6).

In understanding the complexity of living with COPD, it is vital to determine the factors associated with daily activities and quality of life, in addition to physical factors. Non-pharmacological treatment is part of the integrated management of COPD patients. Pulmonary rehabilitation and self-management interventions are reported to improve shortness of breath, health status, exercise tolerance and outcomes in COPD patients (7). As a result, patients should be encouraged to participate in everyday activities and physical exercises in order to adjust to a life with COPD and prevent further physical deterioration. Since patients' willingness and ability to participate in these activities may depend on psychological factors such as illness perception, coping ability, depression and anxiety, these factors merit further study.

Previous research has investigated the effects of anxiety and depression on daily activities and quality of life in COPD patients $(8,9)$, but the relationships of other psychological aspects, such as illness perception and active coping, with daily activities and quality of life in COPD patients remain undetermined.

Patients' quality of life can depend on illness perception, which includes expectations about disease outcomes, selfdescription of disease characteristics, understanding of the disease, worry and mood (10). Those who perceive their likely disease outcome positively and have fewer emotional responses to the condition tend to experience a better quality of life (11). Active coping in COPD patients, including daily exercise, appears crucial in hindering its progression (12). COPD patients with a positive attitude and the knowledge to anticipate future issues are known to have more favorable quality of life, as they are inclined to explore means to improve their lives (13). The relationship of anxiety and depression symptoms with quality of life in COPD patients has been evaluated by many studies but the results have been mixed, possibly because of the varied research methodologies. Katter et al. reported that anxiety and depression are related to limited daily activities and poor quality of life in COPD patients (8). A meta-analysis by Balcells et al. indicated that anxiety and depression symptoms can influence quality of life on timescales beyond one year (9). A study of primary care settings in The
Netherlands linked psychological factors to HRQoL, but not to daily activity (14).

A recent survey in China showed that the prevalence of COPD in rural areas was higher than that in urban areas (3). Ensuring proper treatment of COPD patients is more difficult in rural areas because of economic and geographic obstacles. Most patients stay in their homes and psychological status is often overlooked, including perception of the disease, anxiety, and depression symptoms, all of which can compromise quality of life. Understanding the relationship of psychological factors with daily activities and quality of life could add valuable knowledge for developing an integrated approach to manage COPD patients in rural China.

In the current study we investigated the relationships of psychological factors (illness perception, active coping with the disease, anxiety and depression symptoms) with daily activities and quality of life in COPD patients in rural areas in Sichuan province. We hypothesized that a positive attitude towards the disease, strong active coping skills, and milder anxiety and depression symptoms would be associated with higher daily activity and quality of life. We prepared this article in accordance with the SURGE reporting checklist (available at http://dx.doi.org/10.21037/ apm-20-1151).

\section{Methods}

\section{Patient enrollment and data collection}

A cross-sectional study was performed on a convenience sample of COPD patients from West China Hospital, Sichuan University, who were recruited by doctors from the clinic between September 2012 and October 2013. COPD patients were included if they (I) came from rural areas of Sichuan; (II) were diagnosed with COPD, based on the 2015 Global Initiative for Chronic Obstructive Lung Disease (GOLD) criteria (7), and showed airflow limitation of GOLD 1, 2 or 3; (III) were physically and mentally capable of completing the questionnaire. Patients were excluded if they had asthma, were already participating in other studies or unable to complete the questionnaires. From June 2014 to October 2014, enrolled patients were interviewed by trained doctors by telephone to fill out several surveys. This study was approved by the institutional ethics board of the West China Hospital of Sichuan University (No. 2012266). All participants provided written informed consent. The study conformed to the provisions 
of the Declaration of Helsinki (as revised in 2013).

\section{Survey instruments}

\section{Illness perception}

The Chinese version of the Brief Illness Perception Questionnaire (B-IPQ) (15) was used to evaluate patients' perception of their disease outcome, when their disease began, the degree to which they controlled the disease, the degree to which treatment controlled the disease, the characteristics of their disease, anxiety status, mood, disease understanding, and three causes of their disease. B-IPQ is a self-management scale with nine subscales. Lower scores indicate more positive perception of COPD.

\section{Active response to disease}

The Utrecht Proactive Coping Competence Questionnaire (UPCC) (16) was used to evaluate the degree to which patients actively responded to their disease. The questionnaire contains 21 questions, which respondents answer on a four-point scale from "not competent at all" to "very competent". Higher scores indicate more active coping with the disease.

\section{Anxiety and depression}

The Hospital Anxiety Depression Scale (HADS) (17) was commonly used to assess anxiety and depressive symptoms. The Chinese version of HADS has shown good reliability and validity among patients with somatic diseases (18). The scale includes two subscales, anxiety (HADS-A) and depression (HADS-D), each with 7 questions. Respondents had to select one of four possible responses to indicate their degree of agreement with the item, from "not at all" (scored with 0 points) to "very much indeed" ( 3 points). Higher subscale score indicates greater anxiety or depression. Participants were grouped by subscale score as follows: 0-7 points, normal; $8-10$ points, possible anxiety or depression; 11-21, points, probable anxiety or depression.

\section{Level of dyspnea}

The Modified Medical Research Council (mMRC) (19) scale was used to assess dyspnea on a scale from 0 (no dyspnea occurs without activity) to 4 (dyspnea happens while changing clothes or leaving the house). Higher scores indicate more severe dyspnea.

\section{Daily activities}

The Functional Performance Inventory-Short Form (FPI-
SF) is a commonly used scale for measuring daily activities in COPD patients $(20,21)$. It contains six dimensions comprising 32 items: body care, household maintenance, physical exercises, recreation, spiritual activities and social activities. Subjects answer each question with one of three responses: "the task is easily completed without any difficulty", "the task is not completed due to health problems", or "the task is not completed due to issues unrelated to health". All responses are scored and averaged together. Higher scores indicate poorer daily activities.

\section{Quality of life}

The Clinical COPD Questionnaire (CCQ) (22) measures HRQoL. The questionnaire contains 10 questions addressing functional status, symptoms, and mental status. Respondents answer on a scale ranging from 0 ("no restrictions/no symptom") to 6 ("fully restricted/obvious symptoms"). Higher scores indicate lower quality of life.

\section{Other assessments}

Data were collected from all patients on height, weight, age, sex, education, work status, smoking status, marital status, severity of disease, and medication. Data were also collected on pulmonary function parameters, including forced expiration volume in one second (FEV1, L), forced vital capacity (FVC, L), FEV1\% pre, and FEV1/FVC ratio. The Charlson Comorbidity Index was used to assess complications (23).

\section{Statistical analysis}

Demographics, medications, and comorbidities were reported using descriptive statistics (frequency, mean, and standard deviation). Disease perception, active disease coping, anxiety, depression, pulmonary function indicators, dyspnea, daily activities, and quality of life were reported as mean, standard deviation, and range. Linear regression was performed to explore potential associations of illness perceptions, proactive coping, anxiety and depression with daily activities and quality of life. In this regression, model 1 estimated the associations of illness perceptions, proactive coping, and anxiety and depression with daily activities and quality of life. Model 2 estimated the same relationships as model 1 , while adjusting for age and sex. Model 3 further adjusted for dyspnea, FEV1, smoking status, and complications. In the regression models, the strengths of different independent variables were compared 
Table 1 Patient characteristics

\begin{tabular}{|c|c|}
\hline Variable & Number $(n=86)$ \\
\hline \multicolumn{2}{|l|}{ Sex } \\
\hline Male & $54(62.8 \%)$ \\
\hline Female & $32(37.2 \%)$ \\
\hline \multicolumn{2}{|l|}{ Age (years) } \\
\hline Average & $60.30 \pm 11.2$ \\
\hline$<50$ & $17(19.8 \%)$ \\
\hline $51-60$ & $26(30.2 \%)$ \\
\hline $61-70$ & $29(33.7 \%)$ \\
\hline $71-80$ & $12(14.0 \%)$ \\
\hline$>80$ & $2(2.3 \%)$ \\
\hline Years after COPD diagnosis & $7.86 \pm 1.31$ \\
\hline \multicolumn{2}{|l|}{ Disease severity } \\
\hline GOLD 1 & $63(73.3 \%)$ \\
\hline GOLD 2 & $18(19.8 \%)$ \\
\hline GOLD 3 & $5(7.0 \%)$ \\
\hline FEV1(L) & $2.08 \pm 0.81$ \\
\hline FEV1 \%pre & $92.16 \pm 26.82$ \\
\hline FEV1/FVC \% & $60.81 \pm 10.22$ \\
\hline \multicolumn{2}{|l|}{ Education } \\
\hline Primary school & $61(70.9 \%)$ \\
\hline Middle school & $20(23.3 \%)$ \\
\hline High school & $4(4.7 \%)$ \\
\hline University/tertiary & $1(1.2 \%)$ \\
\hline \multicolumn{2}{|l|}{ Employment status } \\
\hline Employed & $6(7.0 \%)$ \\
\hline Unemployed & $80(93 \%)$ \\
\hline \multicolumn{2}{|l|}{ Marital status } \\
\hline Married & $73(84.9 \%)$ \\
\hline Single & $7(8.1 \%)$ \\
\hline Divorced & $2(2.3 \%)$ \\
\hline Widowed & $4(4.7 \%)$ \\
\hline \multicolumn{2}{|l|}{ Smoking } \\
\hline Previous smoker & $11(12.8 \%)$ \\
\hline Current smoker & $25(29.1 \%)$ \\
\hline Never smoked & $50(58.1 \%)$ \\
\hline Multiple drug treatment $(>5)$ & $19(22.1 \%)$ \\
\hline Charlson Comorbidity Index (>1) & $17(19.8 \%)$ \\
\hline
\end{tabular}

Data are expressed as mean \pm SD or number (\%). COPD, chronic obstructive lung disease; FEV1, forced expiratory volume in one second; FVC, forced vital capacity; GOLD, global initiative for chronic obstructive pulmonary disease. in terms of the standardized regression coefficient $(\beta)$, while relationship strength was assessed in terms of the coefficient of determination $\left(\mathrm{R}^{2}\right)$. All data analyses were performed in SPSS 19.0 (IBM, Chicago, IL, USA).

\section{Results}

\section{Patient characteristics}

Sample characteristics are presented in Table 1. A total of 86 patients met the inclusion criteria and completed the questionnaire. Of the patients in this study, $62.8 \%$ were men, and mean age of the sample was 60.30 (SD 11.2). Most had a primary school education or less $(\mathrm{n}=61 ; 70.9 \%)$, and most were unemployed $(\mathrm{n}=80 ; 93.0 \%)$ and married $(\mathrm{n}=73$; $84.9 \%)$. The respondents had had COPD for an average of 7.86 years (SD 1.3). Most patients had grade 1 disease $(\mathrm{n}=63 ; 73.3 \%)$, and most had been treated with drugs $(\mathrm{n}=70$; $81.4 \%)$.

The means, standard deviations, range of illness perceptions, proactive coping, anxiety and depressive symptoms, dyspnea, FEV1, daily activities, and HRQoL are presented in Table 2. The average score on the FPI-SF was 1.1 (range, 0.32-2.99; reference range, $0-3$ ), indicating intermediate levels of daily activity (20). The average score on the CCQ was 1.29 (range, 0.0-4.9; reference range, 0-6), meaning that the level of HRQoL was generally good (24).

The mean score for illness perception, measured by B-IPQ, was 24.93 (range, 0-54, reference range, 0-80), indicating that the patients had a more positive perception of their disease (25). The mean score for proactive coping was 2.81 (range, 1.2-4.0, reference range, 1.0-4.0), similar to scores typical for healthy adults (26). The mean score for depressive symptoms was 8.93 (range, 0-14; reference range, $0-21$ ). The mean score for anxious symptoms was 8.10 (range, 0-16; reference range, 0-21). Based on the cut-off values recommended by Zigmond and Snaith (27), 33 patients $(38.4 \%)$ had possible depression because their HADS-D subscale score $>8$. Even more patients had an HADS-A subscale score $>8(50,58.1 \%)$, indicating possible anxiety.

\section{Relationships between psychological factors and daily activities}

As shown in Table 3, in the univariate models (model 1), level of daily activities showed relationships with active coping (UPCC; $\beta=-0.696$ ), anxiety (HADS-A; $\beta=0.442$ ), 
Table 2 Psychological wellness and lung functions in COPD patients

\begin{tabular}{lccc}
\hline Subscale or clinical index & Average (SD) & Range & Reference range \\
\hline B-IPQ & $24.93(15.19)$ & $0-54$ & $0-80$ \\
UPCC & $2.81(1.31)$ & $1.2-4.0$ & $1.0-4.0$ \\
HADS-A & $8.10(3.43)$ & $0-16$ & $0-21$ \\
HADS-D & $8.93(3.54)$ & $0-14$ & $0-21$ \\
mMRC & $1.09(1.04)$ & $0-3$ & $0-4$ \\
FEV1(L) & $2.08(0.81)$ & $0.65-4.34$ & $27-112$ \\
FEV \% pre & $92.16(26.82)$ & $0.32-2.99$ & $0-3$ \\
FPI-SF & $1.10(0.61)$ & $0.0-4.9$ & $0-6$ \\
CCQ & $1.29(1.16)$ &
\end{tabular}

B-IPQ, Brief IIIness Perception Questionnaire; UPCC, Utrecht Proactive Coping Competence scale; HADS-A, hospital anxiety and depression scale-anxiety; HADS-D, hospital anxiety and depression scale-depression; mMRC, Modified Medical Research Council dyspnea scale; FEV1, forced expiratory volume in one second; FEV \%pre, forced expiratory volume percentage from predicted; FPI-SF, Functional Performance Inventory Short Form; CCQ, Clinical COPD Questionnaire.

Table 3 Regression analysis to explore associations of disease perception (B-IPQ), positive coping (UPCC), anxiety and depression (HAD) with levels of daily activities (FIP-SF) (n=86)

\begin{tabular}{|c|c|c|c|c|c|c|c|c|c|}
\hline Variables & \multicolumn{3}{|c|}{ Model 1 (block 1) univariate } & \multicolumn{3}{|c|}{ Model 2 (block 1, 2) } & \multicolumn{3}{|c|}{ Model 3 (block 1, 2, 3) } \\
\hline Block1 & & & & 0.616 & & & 0.614 & & \\
\hline B-IPQ & 0.022 & 0.147 & -0.003 to 0.015 & & $0.295^{\star \star \star}$ & 0.006 to 0.018 & & $0.249^{*}$ & 0.001 to 0.019 \\
\hline UPCC & 0.484 & $-0.696^{\star \star \star}$ & -0.396 to -0.251 & & $-0.732^{\star \star \star}$ & $\begin{array}{c}-0.412 \text { to } \\
-0.260\end{array}$ & & $-0.717^{\star \star \star}$ & -0.418 to -0.248 \\
\hline HADS-D & 0.105 & $0.323^{\star \star}$ & 0.020 to 0.092 & & -0.021 & -0.034 to 0.027 & & -0.23 & -0.036 to 0.028 \\
\hline \multicolumn{10}{|l|}{ Block 2} \\
\hline Age & & & & & 0.048 & -0.006 to 0.011 & & 0.048 & -0.007 to 0.013 \\
\hline FEV1 & & & & & & & & 0.011 & -0.151 to 0.168 \\
\hline $\begin{array}{l}\text { Smoking } \\
\text { status }\end{array}$ & & & & & & & & -0.085 & -0.235 to 0.088 \\
\hline Complication & & & & & & & & 0.004 & -0.251 to 0.262 \\
\hline
\end{tabular}

*, $\mathrm{P}<0.05 ;{ }^{* \star}, \mathrm{P}<0.01 ;{ }^{* \star \star}, \mathrm{P}<0.001 ; \mathrm{R}^{2}$, coefficient of determination; $\beta$, standardized regression coefficient; $95 \% \mathrm{Cl}, 95 \%$ confidence interval of unstandardized regression coefficient. Block 1 estimated the association of disease awareness, positive response to disease, and anxiety and depression with daily activities. Block 2 estimated the same relationship as Block 1, while adjusting for age and sex. Block 3 estimated the same relationship as Block 1, further adjusted for dyspnea, FEV1, smoking status, and complications. B-IPQ, Brief Illness Perception Questionnaire; UPCC, Utrecht Proactive Coping Competence scale; HADS-A, hospital anxiety and depression scaleanxiety; HADS-D, hospital anxiety and depression scale-depression; mMRC, Modified Medical Research Council dyspnea scale; FEV1, forced expiratory volume in one second; FPI-SF, Functional Performance Inventory Short Form. 
Table 4 Regression analysis to explore associations of disease perception (B-IPQ), active coping (UPCC), and anxiety and depression (HAD) with quality of life (CCQ)

\begin{tabular}{|c|c|c|c|c|c|c|c|c|c|}
\hline Variables & \multicolumn{3}{|c|}{ Model 1 (block 1) univariate } & \multicolumn{3}{|c|}{ Model 2 (block 1, 2) } & \multicolumn{3}{|c|}{ Model 3 (block 1, 2, 3) } \\
\hline Block 1 & & & & 0.688 & & & 0.724 & & \\
\hline B-IPQ & 0.462 & $0.680^{\star \star \star}$ & 0.040 to 0.064 & & $0.674^{\star \star \star}$ & 0.041 to 0.062 & & $0.550^{\star \star \star}$ & 0.028 to 0.056 \\
\hline UPCC & 0.031 & -0.175 & -0.341 to 0.034 & & $-0.227^{\star \star}$ & -0.327 to -0.071 & & $-0.232^{\star \star}$ & -0.338 to -0.068 \\
\hline HADS-D & 0.026 & 0.16 & -0.018 to 0.122 & & -0.093 & -0.082 to 0.021 & & -0.094 & -0.081 to 0.020 \\
\hline \multicolumn{10}{|l|}{ Block 2} \\
\hline Age & & & & & 0.076 & -0.006 to 0.022 & & -0.018 & -0.018 to 0.014 \\
\hline Sex & & & & & -0.051 & -0.431 to 0.189 & & 0.053 & -0.311 to 0.565 \\
\hline FEV1 & & & & & & & & -0.118 & -0.429 to 0.080 \\
\hline Smoking status & & & & & & & & 0.009 & -0.244 to 0.271 \\
\hline Complication & & & & & & & & -0.07 & -0.613 to 0.207 \\
\hline
\end{tabular}

*, $\mathrm{P}<0.05 ;{ }^{* *}, \mathrm{P}<0.01$; ${ }^{* \star *}, \mathrm{P}<0.001 ; \mathrm{R}^{2}$, coefficient of determination; $\beta$, standardized regression coefficient; $95 \% \mathrm{Cl}, 95 \%$ confidence interval of unstandardized regression coefficient. Block 1 estimated the association of disease awareness, positive response to disease, and anxiety and depression with quality of life. Block 2 estimated the same relationship as Block 1, while adjusting for age and sex. Block 3 estimated the same relationship as Block 1, further adjusted for dyspnea, FEV1, smoking status, and complications. B-IPQ, Brief IIIness Perception Questionnaire; UPCC, Utrecht Proactive Coping Competence scale; HADS-A, hospital anxiety and depression scale-anxiety; HADS-D, hospital anxiety and depression scale-depression; mMRC, Modified Medical Research Council dyspnea scale; FEV1, forced expiratory volume in one second; CCQ, Clinical COPD Questionnaire.

and depression (HADS-D; $\beta=0.323$ ). Illness perception was not associated with level of daily activities. After adjustment for the confounders age and gender in model 2, level of daily activities showed relationships with active coping (UPCC; $\beta=-0.732$ ) and illness perception (B-IPQ; $\beta=0.295$ ), but not with anxiety or depression. In model 3 , level of daily activities still showed relationships with active coping (UPCC; $\beta=-0.717$ ) and illness perception (B-IPQ; $\beta=0.249$ ) after adjustment for the confounders age, gender, dyspnea, FEV1, smoking status, and comorbidity. Illness perception and active coping accounted for $61.4 \%$ of variance in the level of daily activities.

\section{Relationships between psychological factors and HRQoL}

As shown in Table 4, HRQoL showed relationships with illness perception and anxiety in the univariate models in model 1 and in model 2, which combined illness perception, proactive coping, depressive symptoms and anxious symptoms, after correcting for the confounders age and sex; as well as in model 3, which combined the same variables as in model 2, after correcting for the same two confounders as in model 2 in addition to dyspnea, FEV1, smoking status, and comorbidity. HRQoL also showed relationships with active coping in model 2 and with active coping and dyspnea in model 3. Illness perception, active coping, anxiety, and dyspnea accounted for $72.4 \%$ of variance in HRQoL. No relationship was found between depression and HRQoL.

\section{Discussion}

This cross-sectional survey of a small population of COPD patients from rural China suggests that psychological factors relate to both daily activities and HRQoL. More active coping and more positive perception with the disease were associated with a higher level of daily activities based on FIP-SF measurement. More active coping, more positive perception with the disease, less anxiety and less dyspnea 
were associated with better HRQoL.

Active coping and positive illness perception were related to better daily activities in our study. This finding is in accordance with results from previous studies concerning relationships between psychological factors and daily activities (28-30). However, a Dutch study failed to find significant associations of active coping with daily activities or quality of life in COPD patients (14). The discrepancy could be explained by different study populations. Our patients were from rural areas and most had GOLD 1 disease, whereas the patients in the Dutch study were from primary care settings and most had GOLD 2 disease.

Our COPD patients with positive illness perception experienced better quality of life. The finding is consistent with previous reports (31-33). Our new evidence supports the idea that incorporating disease awareness interventions into clinical management of COPD, including regular education and assessment, can improve patient quality of life (32). We found active coping to be associated with better HRQoL. Among key domains of HRQoL for COPD patients (34), self-efficacy is important for improving HRQoL (35-37), and self-efficacy is linked to active coping, use of emotional support, and planning (35). Active coping is also related to better quality of life in other diseases, such as stroke and obesity $(38,39)$.

In our study, $58.1 \%$ of the patients had anxiety symptoms, which is higher than the $40 \%$ prevalence estimated by Kunik (40) and a systematic review by Willgoss (41). This may be explained by the fact that COPD patients in rural areas have lower education levels. Several studies have shown an association between greater anxiety and lower level of education in different diseases (42-44). The present study found that anxiety, but not depression, was related to quality of life. In contrast, a systematic review and a metaanalysis found that both anxiety and depression affect the quality of life of COPD patients (45). The discrepancy may reflect differences in patient populations and survey instruments used. We enrolled patients from rural China, most of whom had GOLD 1 disease. We used the CCQ, which is easier to administer than St. George's Respiratory Questionnaire (SGRQ) (46), while previous studies used the SGRQ and COPD Assessment Test.

We found that dyspnea was related to quality of life in model 3 , consistent with previous research $(47,48)$. Our findings failed to detect a correlation between dyspnea and level of daily activities. Similar results were reported by Tabak et al. (49).

Our work has limitations that should be taken into account when interpreting the findings. As a cross-sectional study, conclusive causal relationships cannot be drawn. Though our sample size was sufficient for the research question, most of the patients had either GOLD 1 or 2 disease. Therefore, subgroup analysis based on COPD grade was not possible. Future work should examine how associations among psychological factors, daily activities and HRQoL may vary across different stages of COPD. Lastly, the $\beta$ coefficients in the regression models were small, suggesting that per unit changes may cause only small clinical changes.

The strength of this research is its representativeness. China has a population of 1.4 billion and more than half live in rural areas (50). The prevalence of COPD is reported to be $14.9 \%$ in rural parts of the country, where the economy and healthcare system are less developed, compared to $12.2 \%$ in urban areas (51). To our knowledge, the current study appears to be the first to focus on psychological factors in COPD patients in the rural Chinese population. Our work also extends the literature by combining different psychological factors in an effort to identify what influences the level of daily activities and HRQoL of COPD patients.

\section{Conclusions}

Better disease perception and less anxiety are related to better quality of life in COPD patients in rural Sichuan, China. Active coping with the disease is associated with higher levels of daily activities. As a chronic disease, COPD requires not only medications but also non-pharmaceutical interventions such as psychological interventions and day-to-day management. Prospective studies should be conducted to further evaluate the role of psychological interventions in COPD management.

\section{Acknowledgments}

Funding: This study was supported by the National Natural Science Foundation of China (81500010), the 1.3 .5 project for Disciplines of Excellence at West China Hospital and the National Key Research and Development Program in China (2016YFC0903600).

\section{Footnote}

Reporting Checklist: The authors have completed the SURGE reporting checklist. Available at http://dx.doi. org/10.21037/apm-20-1151 
Data Sharing Statement: Available at http://dx.doi. org/10.21037/apm-20-1151

Conflicts of Interest: All authors have completed the ICMJE uniform disclosure form (available at http://dx.doi. org/10.21037/apm-20-1151). The authors have no conflicts of interest to declare.

Ethical Statement: The authors are accountable for all aspects of the work in ensuring that questions related to the accuracy or integrity of any part of the work are appropriately investigated and resolved. This study was approved by the institutional ethics board of the West China Hospital of Sichuan University (No. 2012266). All participants provided written informed consent. The study conformed to the provisions of the Declaration of Helsinki (as revised in 2013).

Open Access Statement: This is an Open Access article distributed in accordance with the Creative Commons Attribution-NonCommercial-NoDerivs 4.0 International License (CC BY-NC-ND 4.0), which permits the noncommercial replication and distribution of the article with the strict proviso that no changes or edits are made and the original work is properly cited (including links to both the formal publication through the relevant DOI and the license). See: https://creativecommons.org/licenses/by-nc-nd/4.0/.

\section{References}

1. World Health Organization 2008. The Global Burden of Disease: 2004 Update. Available online: https://www. who.int/healthinfo/global_burden_disease/2004_report_ update/en/

2. Mathers CD, Loncar D. Projections of global mortality and burden of disease from 2002 to 2030. PLoS Med 2006;3:e442.

3. Zhou M, Wang H, Zhu J, et al. Cause-specific mortality for 240 causes in China during 1990-2013: a systematic subnational analysis for the Global Burden of Disease Study 2013. Lancet 2016;387:251-72.

4. Vorrink SN, Kort HS, Troosters T, et al. Level of daily physical activity in individuals with COPD compared with healthy controls. Respir Res 2011;12:33.

5. Janson C, Marks G, Buist S, et al. The impact of COPD on health status: findings from the BOLD study. Eur Respir J 2013;42:1472-83.

6. Schnell K, Weiss CO, Lee T, et al. The prevalence of clinically-relevant comorbid conditions in patients with physician-diagnosed COPD: a cross-sectional study using data from NHANES 1999-2008. BMC Pulm Med 2012;12:26.

7. Global Initiative for Chronic Obstructive Lung Disease - GOLD2015 updated. Available online: https:// goldcopd.org/

8. Katter JK, Greenglass E. The influence of mood on the relation between proactive coping and rehabilitation outcomes. Can J Aging 2013;32:13-20.

9. Balcells E, Gea J, Ferrer J, et al. Factors affecting the relationship between psychological status and quality of life in COPD patients. Health Qual Life Outcomes 2010;8:108.

10. Hartman JE, Boezen HM, de Greef MH, et al. Physical and psychosocial factors associated with physical activity in patients with chronic obstructive pulmonary disease. Arch Phys Med Rehabil 2013;94:2396-2402.e7.

11. Borge CR, Moum T, Puline Lein M, et al. Illness perception in people with chronic obstructive pulmonary disease. Scand J Psychol 2014;55:456-63.

12. Stoilkova A, Wouters EF, Spruit MA, et al. The relationship between coping styles and clinical outcomes in patients with COPD entering pulmonary rehabilitation. COPD 2013;10:316-23.

13. Scharloo M, Kaptein AA, Schlösser M, et al. Illness perceptions and quality of life in patients with chronic obstructive pulmonary disease. J Asthma 2007;44:575-81.

14. Weldam SW, Lammers JW, Decates RL, et al. Daily activities and health-related quality of life in patients with chronic obstructive pulmonary disease: psychological determinants: a cross-sectional study. Health Qual Life Outcomes 2013;11:190.

15. The university of Bergen. The Brief Illness Perception Questionnaire: Chinese version. Available online: http:// www.uib.no/ipq

16. Bode C, de Ridder DT, Kuijer RG, et al. Effects of an intervention promoting proactive coping competencies in middle and late adulthood. Gerontologist 2007;47:42-51.

17. Bjelland I, Dahl AA, Haug TT, et al. The validity of the Hospital Anxiety and Depression Scale. An updated literature review. J Psychosom Res 2002;52:69-77.

18. Zhang GH, Xu MZ, Jin HY, et al. Factorial structure of the Hospital Anxiety and Depression Scale in outpatients with somatic disease. Chinese Journal of Clinical Psychology 2006;14:591-2.

19. Mahler DA, Wells CK. Evaluation of clinical methods for rating dyspnea. Chest 1988;93:580-6. 
20. Leidy NK, Hamilton A, Becker K. Assessing patient report of function: content validity of the Functional Performance Inventory-Short Form (FPI-SF) in patients with chronic obstructive pulmonary disease (COPD). Int J Chron Obstruct Pulmon Dis 2012;7:543-54.

21. Guo AM, Han JN, Leidy NK, et al. Validation of the Chinese version of the Functional Performance Inventory Short Form in patients with chronic obstructive pulmonary disease. J Clin Nurs 2011;20:1613-22.

22. Weldam SW, Schuurmans MJ, Liu R, et al. Evaluation of Quality of Life instruments for use in COPD care and research: a systematic review. Int J Nurs Stud 2013;50:688-707.

23. Charlson M, Szatrowski TP, Peterson J, et al. Validation of a combined comorbidity index. J Clin Epidemiol 1994;47:1245-51.

24. van der Molen T, Willemse B, Schokker S, et al. Development, validity and responsiveness of the clinical COPD questionnaire. Health Qual Life Outcomes 2003;1:13.

25. Broadbent E, Petrie KJ, Main J, et al. The brief illness perception questionnaire. J Psychosom Res 2006;60:631-7.

26. Bode C, Thoolen B, de Ridder D. Measuring proactive coping. Psychometric characteristics of the Utrecht Proactive Coping Competence scale (UPCC). Psychol Gezondheid 2008;36:81-91.

27. Zigmond AS, Snaith RP. The hospital anxiety and depression scale. Acta Psychiatr Scand 1983;67:361-70.

28. Hynninen MJ, Pallesen S, Nordhus IH. Factors affecting health status in COPD patients with comorbid anxiety or depression. Int J Chron Obstruct Pulmon Dis 2007;2:323-8.

29. Fischer M, Scharloo M, Abbink J, et al. The dynamics of illness perceptions: testing assumptions of Leventhal's common-sense model in a pulmonary rehabilitation setting. Br J Health Psychol 2010;15:887-903.

30. Altenburg WA, Bossenbroek L, De Greef MHG, et al. Functional and psychological variables both affect daily physical activity in COPD: A structural equations model. Respir Med 2013;107:1740-7.

31. Weldam SW, Lammers JW, Heijmans MJ, et al. Perceived quality of life in chronic obstructive pulmonary disease patients: a cross-sectional study in primary care on the role of illness perceptions. BMC Fam Pract 2014;15:140.

32. Kaptein AA, Scharloo M, Fischer MJ, et al. Illness perceptions and COPD: an emerging field for COPD patient management. J Asthma 2008;45:625-9.

33. Tiemensma J, Gaab E, Voorhaar M, et al. Illness perceptions and coping determine quality of life in COPD patients. Int J Chron Obstruct Pulmon Dis 2016;11:2001-7.

34. Paap MC, Bode C, Lenferink LI, et al. Identifying key domains of health-related quality of life for patients with chronic obstructive pulmonary disease: the patient perspective. Health Qual Life Outcomes 2014;12:106-18.

35. Wytrychiewicz K, Pankowski D, Bargiel-Matusiewicz $\mathrm{K}$, et al. The role of psychological and medical variables in the process of adaptation to life with chronic illness in a group of COPD outpatients. Psychol Health Med 2019;24:1243-54.

36. Popa-Velea O, Purcarea VL. Psychological factors mediating health-related quality of life in COPD. J Med Life 2014;7:100-3.

37. Hesselink AE, Penninx BW, Schlösser MA, et al. The role of coping resources and coping style in quality of life of patients with asthma or COPD. Qual Life Res 2004;13:509-18.

38. Tielemans NS, Visser-Meily JM, Schepers VP, et al. Proactive coping poststroke: psychometric properties of the Utrecht Proactive Coping Competence Scale. Arch Phys Med Rehabil 2014;95:670-5.

39. Kroese FM, Adriaanse MA, Vinkers CD, et al. The effectiveness of a proactive coping intervention targeting self-management in diabetes patients. Psychol Health 2013;29:110-25.

40. Kunik ME, Roundy K, Veazey C, et al. Surprisingly high prevalence of anxiety and depression in chronic breathing disorders. Chest 2005;127:1205-11.

41. Willgoss TG, Yohannes AM. Anxiety disorders in patients with COPD: a systematic review. Respir Care 2013;58:858-66.

42. Gerogianni G, Lianos E, Kouzoupis A, et al. The role of socio-demographic factors in depression and anxiety of patients on hemodialysis: an observational cross-sectional study. Int Urol Nephrol 2018;50:143-54.

43. Pham T, Jetté N, Bulloch AGM, et al. The prevalence of anxiety and associated factors in persons with multiple sclerosis. Mult Scler Relat Disord 2018;19:35-9.

44. Zhang Y, Muyiduli X, Wang S, et al. Prevalence and relevant factors of anxiety and depression among pregnant women in a cohort study from south-east China. J Reprod Infant Psychol 2018;36:519-29.

45. Blakemore A, Dickens C, Guthrie E, et al. Depression and anxiety predict health-related quality of life in chronic obstructive pulmonary disease: systematic review and meta-analysis. Int J Chron Obstruct Pulmon Dis 2014;9:501-12. 
46. Zhou Z, Zhou A, Zhao Y, et al. Evaluating the Clinical COPD Questionnaire: A systematic review. Respirology 2017;22:251-62.

47. Tsiligianni I, Kocks J, Tzanakis N, et al. Factors that influence disease-specific quality of life or health status in patients with COPD: a review and meta-analysis of Pearson correlations. Prim Care Respir J 2011;20:257-68.

48. Jones P, Miravitlles M, van der Molen T, et al. Beyond FEV1 in COPD: a review of patient-reported outcomes and their measurement. Int J Chron Obstruct Pulmon Dis 2012;7:697-709.

Cite this article as: An J, Zhou H, Yang T, Duan C, Bao C, Wan C, Shen Y, Wen F. Relationship of psychological factors with daily activities and quality of life in patients with chronic obstructive pulmonary disease in a Chinese rural population. Ann Palliat Med 2021;10(2):1675-1684. doi: 10.21037/apm-20-1151
49. Tabak M, Vollenbroek-Hutten MM, van der Valk PD, et al. Telemonitoring of Daily Activity and Symptom Behavior in Patients with COPD. Int J Telemed Appl 2012;2012:438736.

50. Tabulation on the 2010 population census of the people's republic of China. Available online: http://www.stats.gov. $\mathrm{cn} / \mathrm{tjjj} / \mathrm{pcsj} / \mathrm{rkpc} / 6 \mathrm{rp} / \mathrm{indexch} . \mathrm{htm}$

51. Fang L, Gao P, Bao H, et al. Chronic obstructive pulmonary disease in China: a nationwide prevalence study. Lancet Respir Med 2018;6:421-30. 